\title{
Structure and Emergence of Specific Olfactory Glomeruli in the Mouse
}

\author{
Steve M. Potter, ${ }^{1}$ Chen Zheng, ${ }^{2}$ David S. Koos, ${ }^{1}$ Paul Feinstein, ${ }^{2}$ Scott E. Fraser, ${ }^{1}$ and Peter Mombaerts ${ }^{2}$ \\ ${ }^{1}$ Biological Imaging Center, Division of Biology, California Institute of Technology, Pasadena, California 91125, and ${ }^{2}$ The \\ Rockefeller University, New York, New York 10021
}

\begin{abstract}
Olfactory sensory neurons (OSNs) expressing a given odorant receptor (OR) gene project their axons to a few specific glomeruli that reside at recognizable locations in the olfactory bulb. Connecting $\sim 1000$ populations of OSNs to the $\sim 1800$ glomeruli of the mouse bulb poses a formidable wiring problem. Additional progress in understanding the mechanisms of neuronal connectivity is dependent on knowing how these axonal pathways are organized and how they form during development. Here we have applied a genetic approach to this problem. We have constructed by gene targeting novel strains of mice in which either all OSNs or those that express a specific OR gene, M72 or M71, also produce green fluorescent protein (GFP) or a fusion of tau with GFP. We visualized OSNs and their axons in whole mounts with two-photon laser scanning microscopy. The main conclusion we draw from the three-dimensional reconstructions is the high degree of morphological variability
\end{abstract}

of mature glomeruli receiving axonal input from OR-expressing OSNs and of the pathways taken by the axons to those glomeruli. We also observe that axons of OR-expressing OSNs do not innervate nearby glomeruli in mature mice. Postnatally, a tangle of axons from M72-expressing OSNs occupies a large surface area of the bulb and coalesces abruptly into a protoglomerulus at a reproducible stage of development. These results differ in several aspects from those reported for the development of glomeruli receiving input from OSNs expressing the P2 OR, suggesting the need for a more systematic examination of OR-specific glomeruli.

Key words: olfaction; olfactory system; olfactory bulb; glomerulus; sensory neuron; olfactory receptor; odorant receptor; tau; green fluorescent protein; two-photon microscopy; axon guidance
Neurons must make, from an immense array of options, specific choices of where to project their axons and where to form synapses with other neurons. Historically, sensory systems have provided many of our insights into the wiring of the brain because of their accessibility and well characterized, orderly projections. The cloning of odorant receptor (OR) genes (Buck and Axel, 1991; Mombaerts, 1999) has provided powerful new tools to study the mechanisms of axon guidance in the olfactory system (Mombaerts, 2001).

Odorants interact with ORs on the surface of olfactory sensory neurons (OSNs). The OR repertoire is encoded by the largest mammalian gene family, comprising as many as 1000 genes in mouse and rat (Mombaerts, 1999a,b) and human (Mombaerts, 2000). An individual OSN expresses most likely a single OR gene (Malnic et al., 1999). OSNs expressing a given OR are segregated within one of four zones of the olfactory epithelium, where they are interspersed with OSNs expressing other ORs (Ressler et al.,

\footnotetext{
Received July 2, 2001; revised Sept. 17, 2001; accepted Sept. 20, 2001.

This work was supported by the Beckman Institute (S.M.P., D.S.K., S.E.F.), the National Institutes of Health (NIH) (S.M.P., S.E.F., P.M.), and the Human Frontier Science Program (P.M.). Postdoctoral fellowship support was provided by The Norman and Rosita Winston Foundation (C.Z.), Bristol-Myers Squibb, the Kirby Center for Sensory Neuroscience at The Rockefeller University (P.F.), and NIH (C.Z., P.F.). P.M. was an Alfred P. Sloan, Basil O'Connor, Guggenheim, Irma T. Hirschl, Klingenstein, McKnight, Rita Allen, and Searle scholar or fellow. We thank Karel Svoboda, Rafa Yuste, Kai Zinn, and in particular Charles Greer for discussions and thoughtful comments on this manuscript. We thank Janet Baer, David Crotty, and Mary Flowers (Caltech) for logistical help in mouse shipments. We acknowledge Clontech for providing enhanced GFP-1 before commercial release.

All authors contributed equally to this work.

Correspondence should be addressed to Peter Mombaerts, The Rockefeller University, 1230 York Avenue, New York, New York 10021. E-mail: peter@ rockefeller.edu.

Copyright (ㄷ) 2001 Society for Neuroscience $\quad 0270-6474 / 01 / 219713-11 \$ 15.00 / 0$
}

1993; Vassar et al., 1993). OSNs expressing a given OR project their axons to a few specific glomeruli in the olfactory bulb (Ressler et al., 1994; Vassar et al., 1994; Mombaerts et al., 1996a) of $\sim 1800$ choices (Royet et al., 1988). Glomerular convergence at the single-axon level was first demonstrated for P2-expressing OSNs in gene-targeted mice (Mombaerts et al., 1996a,b), in which their axons can be stained selectively by virtue of the coupling of P2 expression to that of the axonal marker taulacZ (Callahan and Thomas, 1994).

The wiring of the mammalian olfactory system may follow different principles than that of other model systems such as moth (Oland and Tolbert, 1996) and zebrafish (Dynes and Ngai, 1998) because of its much greater numerical complexity. Classic studies of rat (Valverde et al., 1992; Bailey et al., 1999; Treloar et al., 1999), opossum (Malun and Brunjes, 1986), and mouse (LaMantia and Purves, 1989; LaMantia et al., 1992; Puche and Shipley, 2001) described randomly chosen glomeruli, because the tools to study OR-specific glomeruli were not available. In a study of P2-IRES-taulacZ mice (Royal and Key, 1999), axonal targeting to a specific site in the bulb was observed as early as embryonic day 15.5 , and the P2 glomeruli were reported to emerge slowly, via a process that involves some errors in axonal pathfinding. However, because P2-expressing OSNs represent 1 of $~ 1000$ OSN subsets, it remains to be determined whether this scenario pertains to other OSN populations expressing different ORs. Indeed, pronounced differences have been observed between populations of OSNs; for instance, we reported (Zheng et al., 2000) that disruption of cyclic nucleotide-gated channel function has a differential impact on P2 glomeruli (apparently normal) and M72 glomeruli (dispersed). 
Here, we examine the structure and emergence of OR-specific glomeruli with two-photon laser scanning microscopy. We observe a high degree of morphological variability in mature M72 and M71 glomeruli and their axonal plexuses. Few or no axons are misrouted to nearby glomeruli in mature mice. M72 glomeruli form abruptly at a reproducible developmental stage.

\section{MATERIALS AND METHODS}

Targeted mutations. To construct the $O M P$-GFP-targeting vector, a GFP/ $L T N L$ cassette was inserted into a generic $O M P$-targeting vector (Mombaerts et al., 1996a). The version of green fluorescent protein (GFP) used was enhanced GFP-1 (Clontech, Cambridge, UK). The targeted mutation in the olfactory marker protein $(O M P)$ locus was obtained in the embryonic stem cell line E14 (Hooper et al., 1987) at high frequency. The neo-selectable marker was subsequently removed from clone M55 by transient expression of the site-specific recombinase Cre and negative selection with ganciclovir against herpes simplex virus-thymidine kinase (HSV-tk) expression. Clone M55/Cre7 was injected into C57BL/6 blastocysts; germ line transmission was obtained; and heterozygous and homozygous $O M P$-GFP mice (strain M55/Cre7) were produced. Mice were in a mixed $129 \times \mathrm{C} 57 \mathrm{BL} / 6$ background. Care of mice was in accordance with institutional guidelines.

The $M 72$ gene was identified by us as a homolog of the mouse $M 71$ OR gene (Ressler et al., 1994). A phage library, derived from mice of the $129 / \mathrm{Sv}$ strain, was screened and yielded clones from which various restriction fragments were subcloned. A PacI restriction site was engineered three nucleotides downstream of the stop codon of $M 72$ by recombinant PCR, and an IRES-tauGFP-LNL (Strotmann et al., 2000) cassette was inserted in that site. Homologous recombination at the $M 72$ locus was achieved at high frequency. Clone T15 was used to generate germ line chimeras. The loxP-flanked neo-selectable marker was removed from the targeted mutation by crossing heterozygous mice with transgenic mice expressing the Cre recombinase ubiquitously (Lakso et al., 1996) and back-crossed multiple times to C57BL/6 mice. The Cre transgene was subsequently removed from the strain by outbreeding, yielding strain T15/loxP. Similar results were obtained with strain T41/Cre37, carrying originally an M72-IRES-tauGFP-LTNL mutation, from which subsequently the tk-neo gene was removed by Cre-mediated excision in embryonic stem cells. Mice were in a mixed $129 \times$ C57BL/6 background.

The $M 71$ gene (Ressler et al., 1994) was modified by targeted insertion of an IRES-tauGFP-LTNL cassette (Rodriguez et al., 1999), similar to the construction of the M72-IRES-tauGFP mutation.

Specimen preparation and imaging. Mice were killed by cervical dislocation and dissected under a stereomicroscope. The mice were decapitated, and the lower jaw was removed. For imaging of the olfactory epithelium with the upright two-photon microscope, the head was bisected along the midline, and half of a head was placed in a $60 \mathrm{~mm}$ dish with the eye down and immobilized using dental wax. For imaging of the olfactory bulb, the dissected head was stabilized dorsal side-up in a dish. Artificial CSF (125 mm NaCl, $2.5 \mathrm{~mm} \mathrm{KCl}, 1 \mathrm{~mm} \mathrm{MgCl}_{2}, 2 \mathrm{mM} \mathrm{CaCl}_{2}$, $1.25 \mathrm{~mm} \mathrm{NaH}_{2} \mathrm{PO}_{4}, 26 \mathrm{~mm} \mathrm{NaHCO}_{3}, 25 \mathrm{~mm}$ glucose, and $5 \mathrm{mg} / \mathrm{ml}$ phenol red, gassed with $95 \% \mathrm{O}_{2}$ and $5 \% \mathrm{CO}_{2}$ ) flooded the tissues and was replaced every $30 \mathrm{~min}$. Areas of interest in the bulb were identified with a low-power objective under epifluorescence illumination by a tungsten lamp. Laser scanning was performed with $25 \times, 0.8$ numerical aperture or $40 \times, 0.75$ numerical aperture Zeiss (Thornwood, NY) Plan-Neofluar water immersion lenses ( 0.8 and $0.5 \mu \mathrm{m}$ pixel size, respectively). All images shown here were produced with the $40 \times$ lens and measured 256 $\mu \mathrm{m}$ across. Images were obtained as early as $10 \mathrm{~min}$ after killing the mouse and as late as after $4 \mathrm{hr}$ without apparent degeneration of the structures or decrease of the intensity of the fluorescence. This method of dissecting and positioning the head ensures that imaging is performed from a comparable perspective between different specimens. Another advantage of the nasal-attached whole-mount preparation is that there may be less damage, because axons remain intact from epithelium to bulb.

Our analysis focused on the major, primary M72 glomeruli and not on the smaller, additional M72 glomeruli that are occasionally observed (Zheng et al., 2000). PD1 is defined as the day on which the pups were found to be born, PD2 as the next day, and so on.

The two-photon laser scanning microscopy (TPLSM) setup, a converted Molecular Dynamics (Sunnyvale, CA) Sarastro 2000 confocal laser scanning microscope, has been described in detail previously (Potter et al., 1996; Potter, 2000). We substituted the laser of the confocal microscope with a tunable Ti-sapphire laser (Coherent Mira 900), pumped by a solid-state Coherent Verdi laser. Excitation was at $850-900 \mathrm{~nm}$. Images were acquired using a Silicon Graphics Indigo computer. Data were $3 \times 3$ median-filtered; this type of filtering has the least blurring effect of available filters. Images were then projected using ImageSpace software (Molecular Dynamics) on a Silicon Graphics $\mathrm{O}_{2}$ computer. Images were colorized on a Macintosh computer (Apple, Cupertino, CA) with Adobe (Mountain View, CA) Photoshop 5. MacVol (http://strout.net/macsoft $/ \mathrm{macvol}$ ) was used to produce surface renderings.

\section{RESULTS \\ The OMP-GFP mouse}

To overcome limitations in sensitivity and resolution of the axonal marker taulacZ, we developed a new method for imaging specific neuronal populations in unfixed, acutely dissected specimens. This approach is based on GFP (Chalfie et al., 1994; Tsien, 1998) and TPLSM (Denk et al., 1990; Denk and Svoboda, 1997). Constructs based on the coding sequence of GFP or the many variants that have now been engineered allow cells to produce their own, genetically encoded, fluorescent label. TPLSM enables repeated three-dimensional imaging of thick, live biological specimens (Potter, 1996; Potter et al., 1996). With this technology, it is possible to excite selectively a single focal plane even within highly scattering tissues and to collect the fluorescent signals far more efficiently and with much less damage to fluorophores and tissues than with confocal or wide-field fluorescence microscopy.

We first tested the performance of GFP (without fusion to tau) and TPLSM in the mouse olfactory system by constructing a gene-targeted mouse strain in which GFP is expressed from the locus encoding OMP (Fig. 1A). OMP is expressed at high levels and selectively in mature OSNs (Margolis, 1972); its function remains enigmatic. In $O M P$-taulac $Z$ mice, all OSNs including their axons and axon terminals can be stained intensely blue with 5 -bromo-4-chloro-3-indolyl- $\beta$-D-galactopyranoside, providing an overview of the anatomy of the mouse olfactory system (Mombaerts et al., 1996a). We thus followed the same strategy using GFP and TPLSM. In OMP-GFP mice, GFP is expressed in abundance in OSNs within the epithelium (Fig. 2A-D); individual cellular components are clearly visible. GFP labels the OSN axons down to their terminals within the glomeruli of the bulb (Fig. 3A,B). The intense fluorescence can be detected in the nasal cavity and the bulb with an epifluorescence stereomicroscope, even through the skull of an adult mouse.

TPLSM whole-mount imaging of the olfactory epithelium covering the turbinates demonstrates both the dramatic images resulting from this technique and the organization of the OSNs in the periphery. Clear images of individual dendritic knobs, individual cell bodies, individual axons, and axon bundles are obtained in successive optical sections (Fig. $2 E-H$ ). In section series, individual OSNs can be followed in their entirety, demonstrating unambiguously that the TPLSM technique provides single-axon detection of OSNs at the level of the epithelium (animation 1, available at www.jneurosci.org).

TPLSM optical sections of the olfactory bulb reveal the glomeruli at different levels as globose structures of widely varying shapes and sizes (Fig. 3C,D). This is best appreciated in successive sections of a series (animations 2 and 3, available at www.jneurosci. org). Superficial to the glomerular layer is a dense network of ribbon-like fascicles of axons resembling a woven basket but without obvious direction or organization (Fig. 3C); this has been termed "feltwork" (Ramón y Cajal, 1911). At adult stages (animation 2, available at www.jneurosci.org), the nerve fiber layer is 


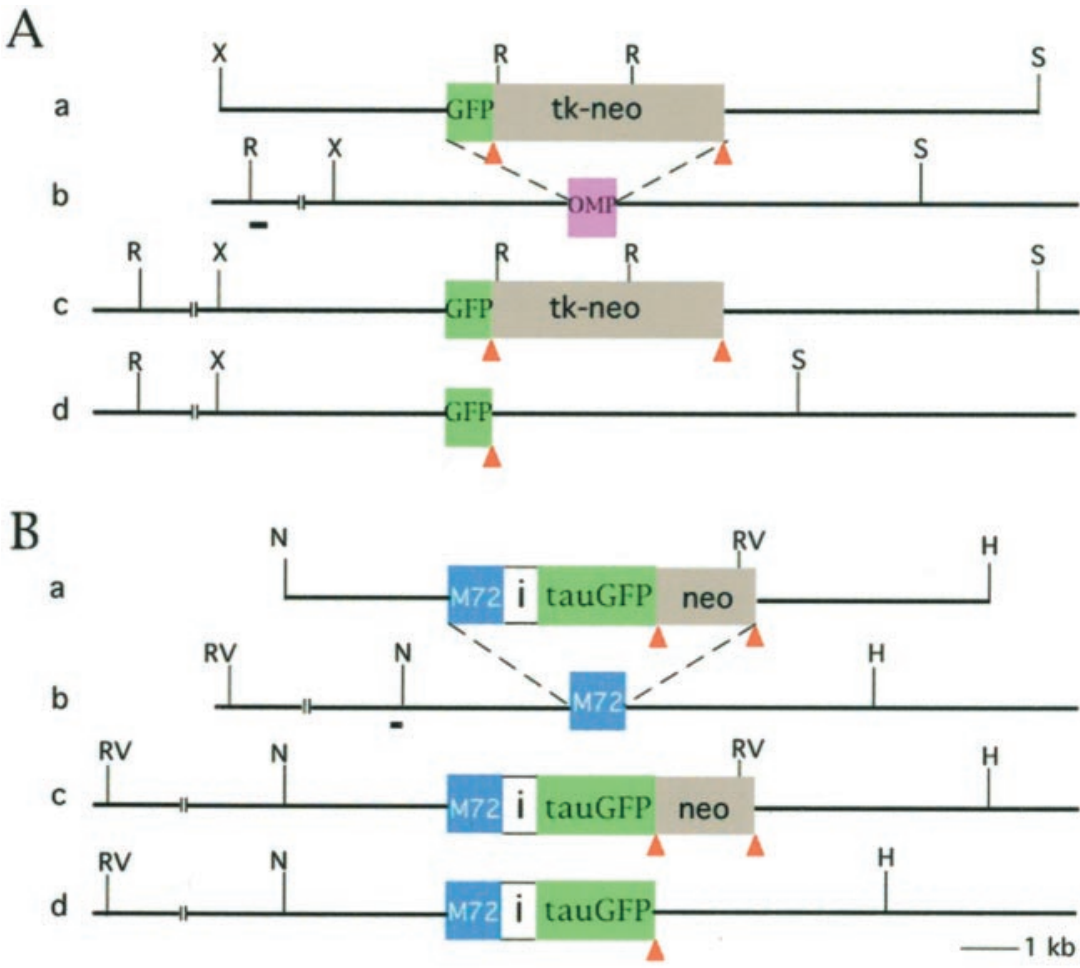

C

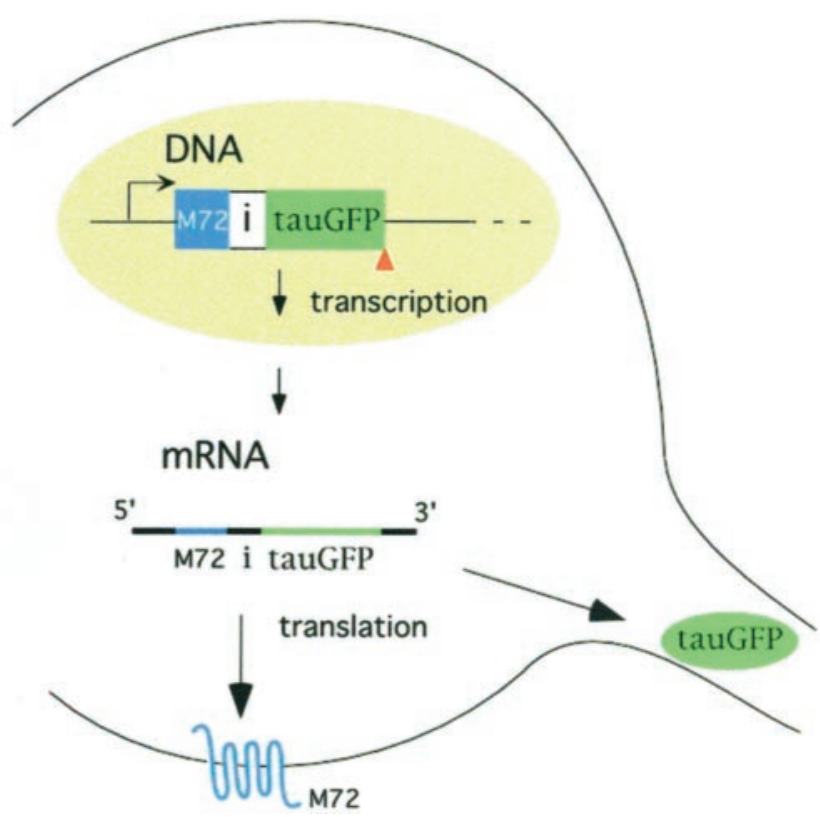

Figure 1. Genetic approach. $A$, Targeted mutagenesis of the OMP locus. $a, O M P-G F P-L T N L$ targeting vector. The green box (GFP) represents the coding sequence of the GFP gene. The gray box (tk-neo) represents the negative selectable marker $H S V$-tk followed by the positive selectable marker pgk-neo, flanked by loxP sites (red triangles). The relevant restriction sites are indicated as $X(X h o \mathrm{I}), R(E c o \mathrm{RI})$, and $S(S p h \mathrm{I}) . b$, Wild-type $O M P$ locus. The pink box $(O M P)$ indicates the coding sequence of the $O M P$ gene and 150 nucleotides of the $3^{\prime}$ noncoding region. The black bar on the left represents the $5^{\prime}$ external probe used to detect homologous recombination at this locus by Southern blot analysis. $c, O M P$ locus after homologous recombination. $d$, OMP locus after Cre recombination. $B$, Targeted mutagenesis of the $M 72$ locus. $a, M 72-I R E S$-tauGFP-LNL targeting vector. The blue box (M72) represents the coding sequence of the M72 OR gene. The white box (i) represents the IRES sequence. The green box (tauGFP) represents the coding sequence of the tauGFP fusion. The gray box (neo) represents the selectable marker pgk-neo flanked by loxP sites (red triangles). The relevant restriction sites are indicated as $N$ (NdeI), $R V$ (EcoRV), and $H$ (HindIII). $b$, Wild-type $M 72$ locus. $c, M 72$ locus after homologous recombination. $d, M 72$ locus after Cre recombination. $C$, Diagram of bicistronic design. When a neuron chooses, by an unknown process, the mutant M72-IRES-tauGFP allele for expression, a bicistronic transcript is produced in the nucleus that is exported to the cytoplasm. Ribosomes translate two polypeptides from this message: the M72 OR protein (a 7-transmembrane protein) and the tauGFP fusion protein (a fluorescent axonal marker). Cotranslation of both the receptor and the reporter is mediated by the IRES sequence. The M72 OR protein is targeted to the plasma membrane. The tauGFP marker binds to microtubules, which are present abundantly in axons and axon terminals. considerably more organized than in younger mice (animation 3 , available at www.jneurosci.org). The complexity of the outer nerve layer underscores the challenges faced by OSN axons in navigating from the epithelium to their glomerular targets in the bulb.

\section{The M72-IRES-tauGFP mouse}

To visualize glomeruli and axonal plexuses specific for a particular OR, we next generated a strain of mice expressing tauGFP from a specific OR locus. We chose the M72 OR gene primarily because the M72 glomeruli map to the dorsal surface of the olfactory bulb (Zheng et al., 2000), an area that is readily accessible for anatomical and physiological investigations. tauGFP was used because fusion of GFP to tau enhances axonal decoration (Brand, 1995; our unpublished observations). The M72-IREStauGFP strain (Fig. $1 B, C$ ) was generated by targeted mutagenesis using an IRES-tauGFP cassette (Strotmann et al., 2000). In histological sections of the epithelium, sporadic green fluorescent cells are observed throughout the appropriate zone (data not 

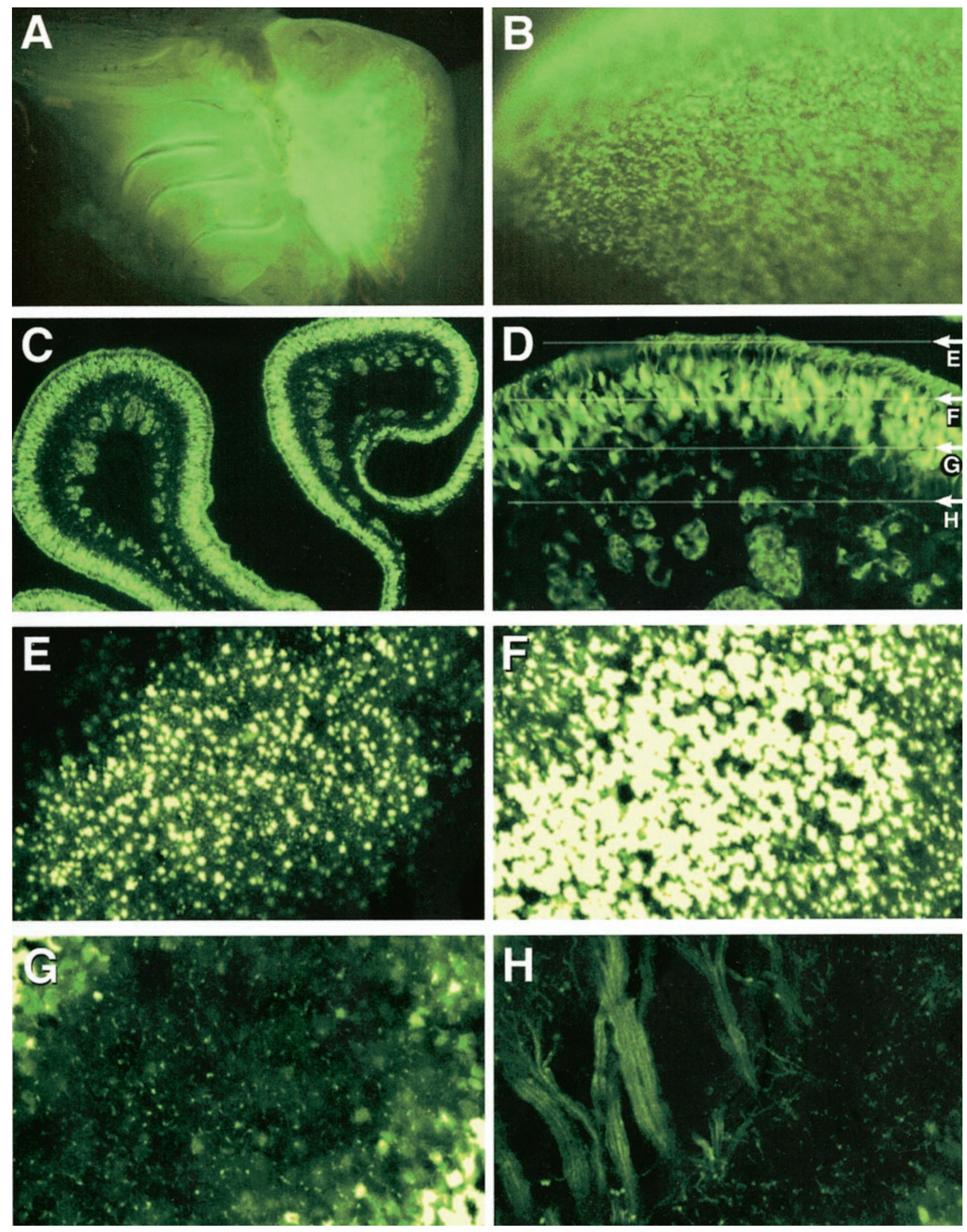

Figure 2. Olfactory epithelium of $O M P$-GFP mice. $A$, Medial whole-mount view of a half-head of an adult mouse. Olfactory epithelium (left) and olfactory bulb (right) are intensely fluorescent. Images were photographed using an epifluorescence stereomicroscope (Leitz MZ12; Leitz, Stuttgart, Germany). Image width, $6 \mathrm{~mm}$. $B$, Close-up whole-mount view of the olfactory epithelium. Green dots represent OSNs; dark areas correspond to the non-GFP-expressing supporting cells. Images were photographed using a Leitz MZ12 stereomicroscope. Image width, $\sim 1 \mathrm{~mm}$. $C$, Low-power view of a histological section through the nose. Green fluorescent OSNs line the convoluted surface of the turbinates. Their axons are assembled in bundles underneath the epithelium. Images were photographed using an epifluorescence wide-field microscope (Zeiss Axioplan 2). (Figure legend continues.) 

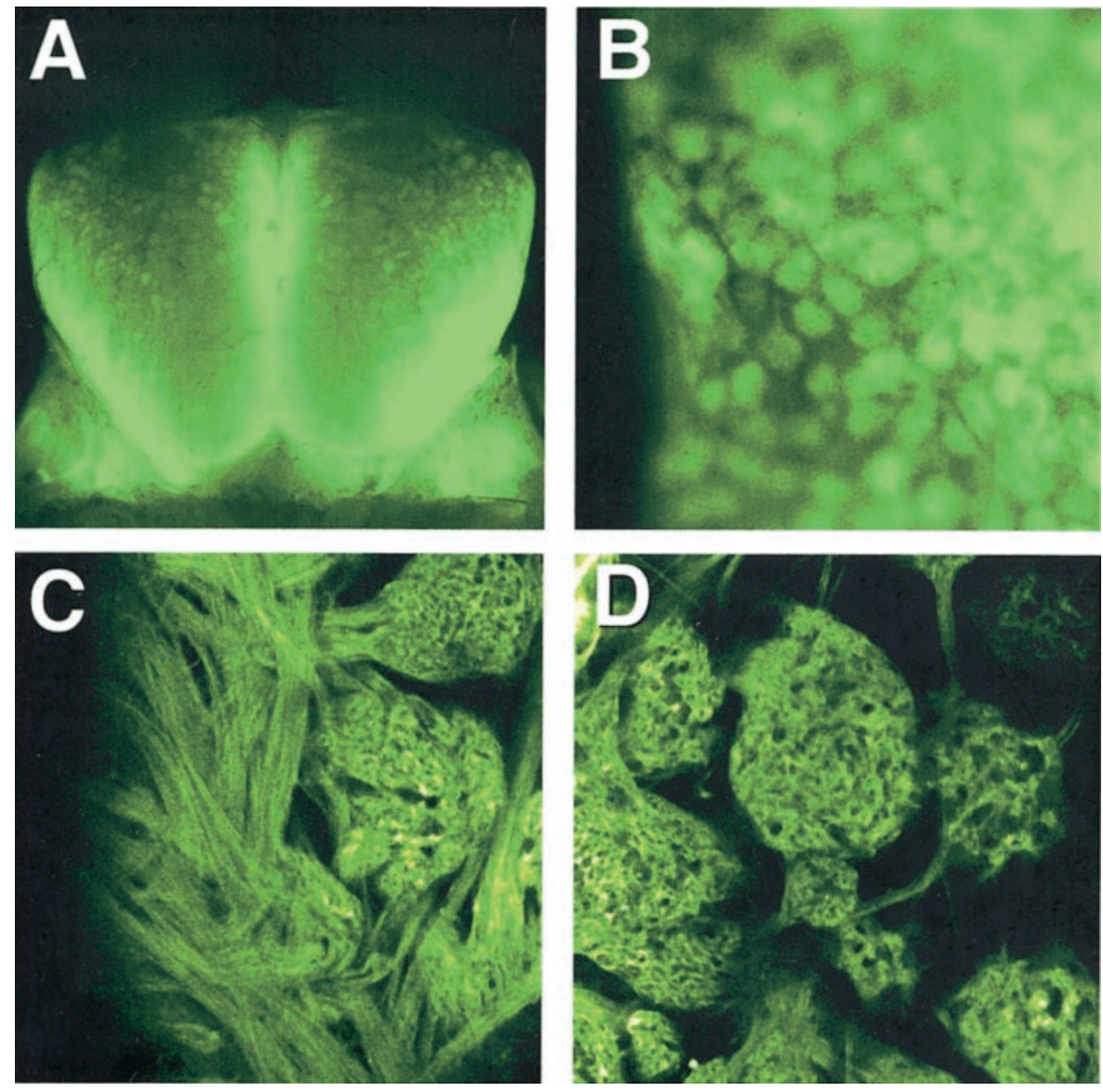

Figure 3. Olfactory bulb of $O M P-G F P$ mice. $A$, Whole-mount view of the dorsal surface of both olfactory bulbs. Top is posterior; bottom is anterior. The outer nerve layer and the glomerular layer produce intense fluorescence that is easily detectable with an epifluorescence stereomicroscope (Zeiss Stemi SV11). Image width, $5 \mathrm{~mm}$. B, Close-up whole-mount view of glomeruli in the olfactory bulb, photographed with an epifluorescence stereomicroscope (Zeiss Stemi SV11). Image width, $\sim 1.2 \mathrm{~mm}$. $C$, Optical section at the level of the glomerular layer (right) and the outer nerve layer (left) produced by TPLSM. Glomeruli are discrete globose structures covered with a thick mat of fibers running across the surface of the bulb without obvious direction or stereotyped organization. Image width, $\sim 256 \mu \mathrm{m}$. $D$, Optical section at the level of the glomeruli, below the outer nerve layer, produced by TPLSM. The nonfluorescent areas inside the glomeruli presumably correspond to the dendrites of interneurons and second-order neurons and to glia and blood vessels, which do not express OMP and thus do not express GFP in these mice. Image width, $\sim 256 \mu \mathrm{m}$. shown). In whole-mount epifluorescence microscopy, the major M72 glomeruli are visible typically as a pair of green fluorescent structures residing at recognizable, bilaterally symmetric positions in the medial and lateral hemispheres of the bulb (Fig. $4 A, B)$. This pattern is also observed typically in mice with a targeted M72-IRES-taulacZ mutation (Zheng et al., 2000); furthermore, axons of M72-IRES-taulacZ-expressing OSNs coconverge with those of M72-IRES-tauGFP-expressing OSNs to the same glomeruli (data not shown).

For TPLSM studies of mature mice, we imaged a set of 14 glomeruli and axonal plexuses in the lateral hemisphere from 10 M72-IRES-tauGFP mice at postnatal day 18 (PD18) or older. Imaging an entire glomerulus requires collecting a series of optical sections of $\sim 250 \mu \mathrm{m}$ across and $100-200 \mu \mathrm{m}$ in depth; this depth exceeds the capabilities of confocal laser scanning microscopy. In section series, incoming fibers can be traced in three dimensions (animation 4, available at www.jneurosci.org). Threedimensional stereo projections reveal a remarkable degree of morphological variability of the axonal plexus that converges on an M72 glomerulus (Figs. $4 C-E, 5$; animations 5-8, available at www.jneurosci.org). The network of anastomosing and interlac- ing fibers approaches the glomeruli in a seemingly random but directed manner. Some M72 glomeruli receive their axonal input in the form of a very few fascicles, which become thicker as they approach the glomerulus (Fig. 4C,D; animations 5 and 6, available at www.jneurosci.org). Others are innervated by multiple smaller fascicles that converge from all directions onto a common target (Figs. 4E, 5; animation 7, available at www.jneurosci.org). Labeled fibers frequently approach the glomerulus along a contorted path or loop back after bypassing the glomerulus (Fig. 5D,F; animation 8, available at www.jneurosci.org). Many of these fibers appear similar in intensity and size to the single axons seen emerging from OSN cell bodies (Fig. 2G). Similarly, the M72 glomeruli display extensive phenotypic variability. No two reconstructions look alike, even within an individual mouse, as exemplified by reconstructions of the right (Fig. $4 C$; animation 5, available at www.jneurosci.org) and left (Fig. 4D; animation 6, available at www.jneurosci.org) lateral glomeruli of the same mouse. The variability seen between the bulbs of a single mouse argues against differences in genetic background or sensory experience causing the observed polymorphism.

Our initial imaging of $\mathrm{P} 2$ glomeruli in mature P2-IRES-taulacZ

Image width, $\sim 1.4 \mathrm{~mm} . D$, Medium-power view of a histological section through the nose. The horizontal white lines indicate the approximate levels of the optical sections shown in $E-H$. Images were photographed using a confocal laser scanning microscope (Zeiss LSM 510). Image width, $\sim 256 \mu \mathrm{m}$. $E$, Optical section through OSN dendrites produced by TPLSM from a 4-d-old mouse. Individual dendritic knobs are visible. Image width, $\sim 256 \mu$ m. $F$, Optical section at the level of the cell bodies of OSNs produced by TPLSM. Image width, $\sim 256 \mu \mathrm{m}$. $G$, Optical section at the level of the axons of the cell bodies produced by TPLSM. Single axons are clearly visible, even when imaged through the brightly labeled cell body layer, which saturated the detector. Image width, $\sim 256 \mu \mathrm{m}$. $\mathrm{H}$, Optical section at a level below the epithelium produced by TPLSM. OSN axons coalesce to form ribbon-like fascicles. Image width, $\sim 256 \mu \mathrm{m}$. 

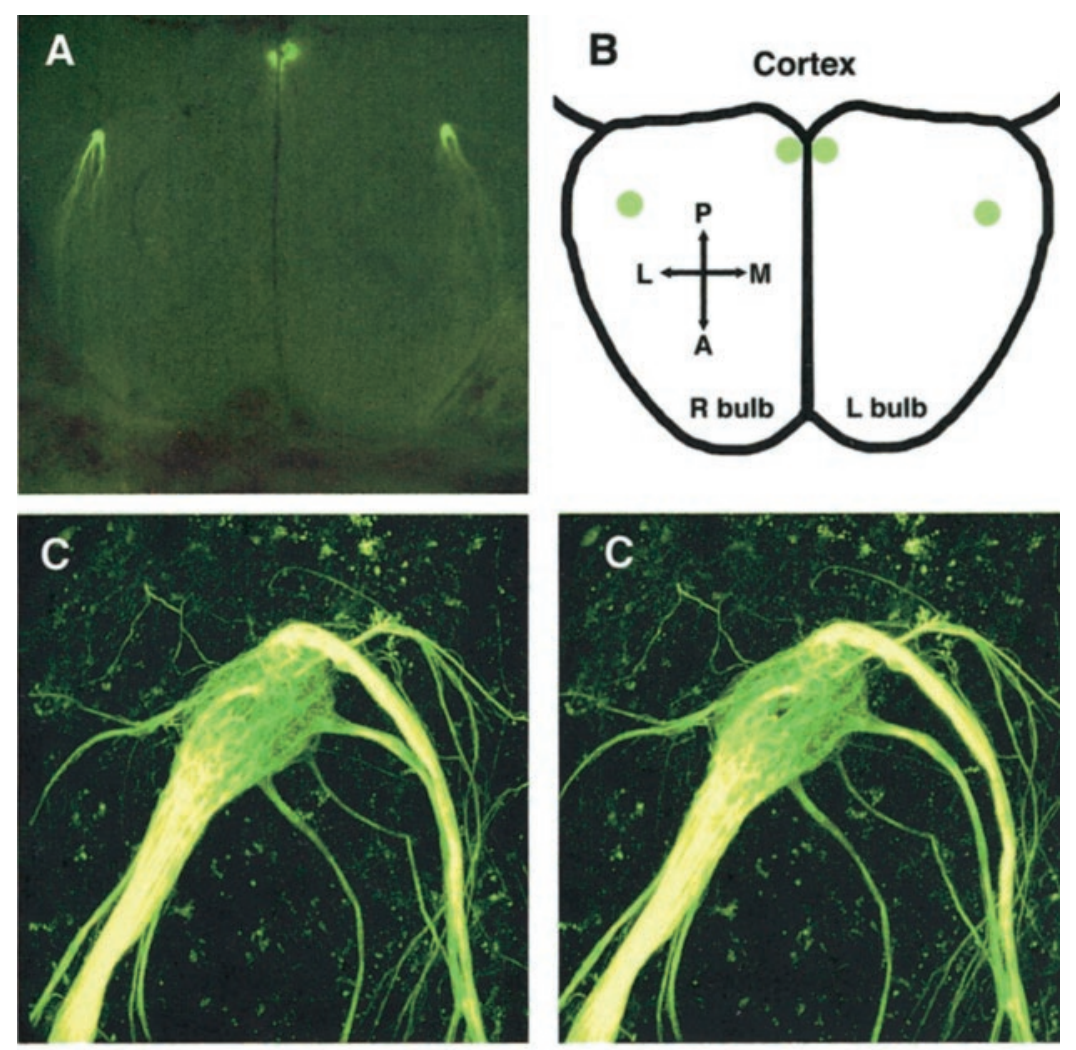

Figure 4. M72 glomeruli in M72-IRES-tauGFP mice. A, Whole-mount view of the dorsal surface of the olfactory bulbs of a mature M72-IRES-tauGFP mouse. Orientation is identical to that in Figure $3 A$. A pair of medial and lateral green fluorescent glomeruli can be discerned within each bulb. This study concentrated on the lateral M72 glomeruli because they reside in a flattened region of the dorsal surface of the olfactory bulb and are readily accessible for imaging. The dark lines are blood vessels within the meningi. Images were photographed using an epifluorescence stereomicroscope (Zeiss Stemi SV11). Image width, $5 \mathrm{~mm}$. $B$, Schematic representation of image shown in $A$. $P$, Posterior; $M$, medial; $A$, anterior; $L$, lateral, $R$, right; $L$, left. The interbulbar symmetry of the positions of the M72 glomeruli is apparent. The intrabulbar symmetry of the positions of the M72 glomeruli is along a plane that intersects with the midline at an $\sim 30^{\circ}$ angle, such that the lateral glomeruli are more anterior and more dorsal than the medial glomeruli. $C$, Stereo pair of three-dimensional TPLSM reconstruction of the right lateral glomerulus of a PD18 M72-IRES-tauGFP mouse (strain T15/loxP). A few major fascicles terminate in the glomerulus. Image width, $\sim 256 \mu \mathrm{m}$. D, Stereo pair of the left lateral glomerulus of the mouse shown in $C$. There is no bilateral symmetry; the pattern of fascicles is different from that in $C$. Image width, $\sim 256 \mu \mathrm{m}$. E , Stereo pair of a lateral glomerulus from a PD18 M72-IRES-tauGFP mouse, a littermate of the mouse shown in $C$ and $D$. Multiple small fascicles converge onto the glomerulus from widely varying angles. Image width, $\sim 256 \mu \mathrm{m}$.
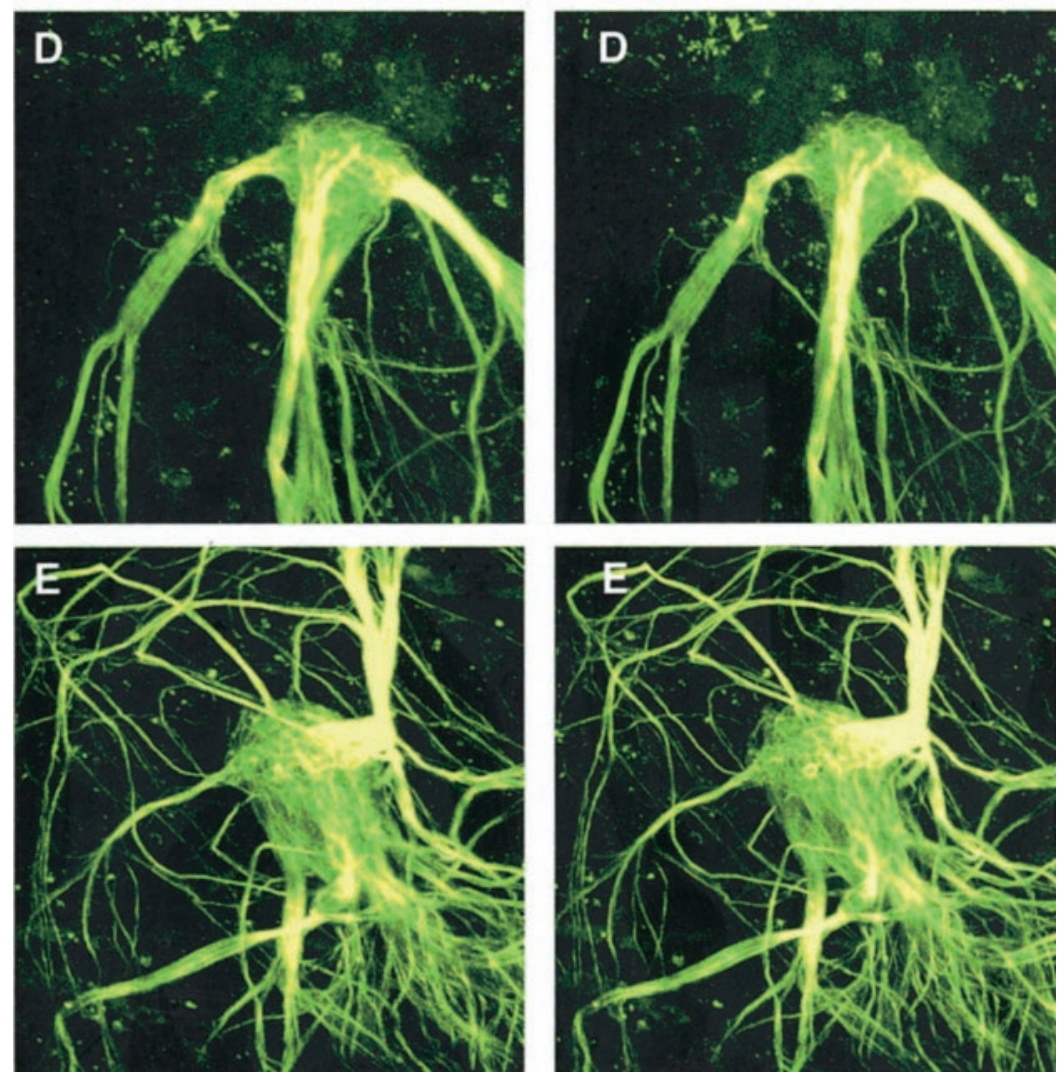

mice led us to suggest that all axons from OSNs expressing a given OR terminate within a few specific glomeruli (Mombaerts et al., 1996a). It was subsequently reported that during development but not in adulthood, some axons do not target properly (Royal and Key, 1999). The improved quality of the images of
M72 glomeruli and axonal plexuses provided by TPLSM permit us to confirm and extend, with a greater degree of certainty, that no axons of M72-expressing OSNs in mature mice terminate in glomeruli within a radius of a few glomeruli from the M72 glomeruli; axonal convergence is extremely precise at PD18. This 

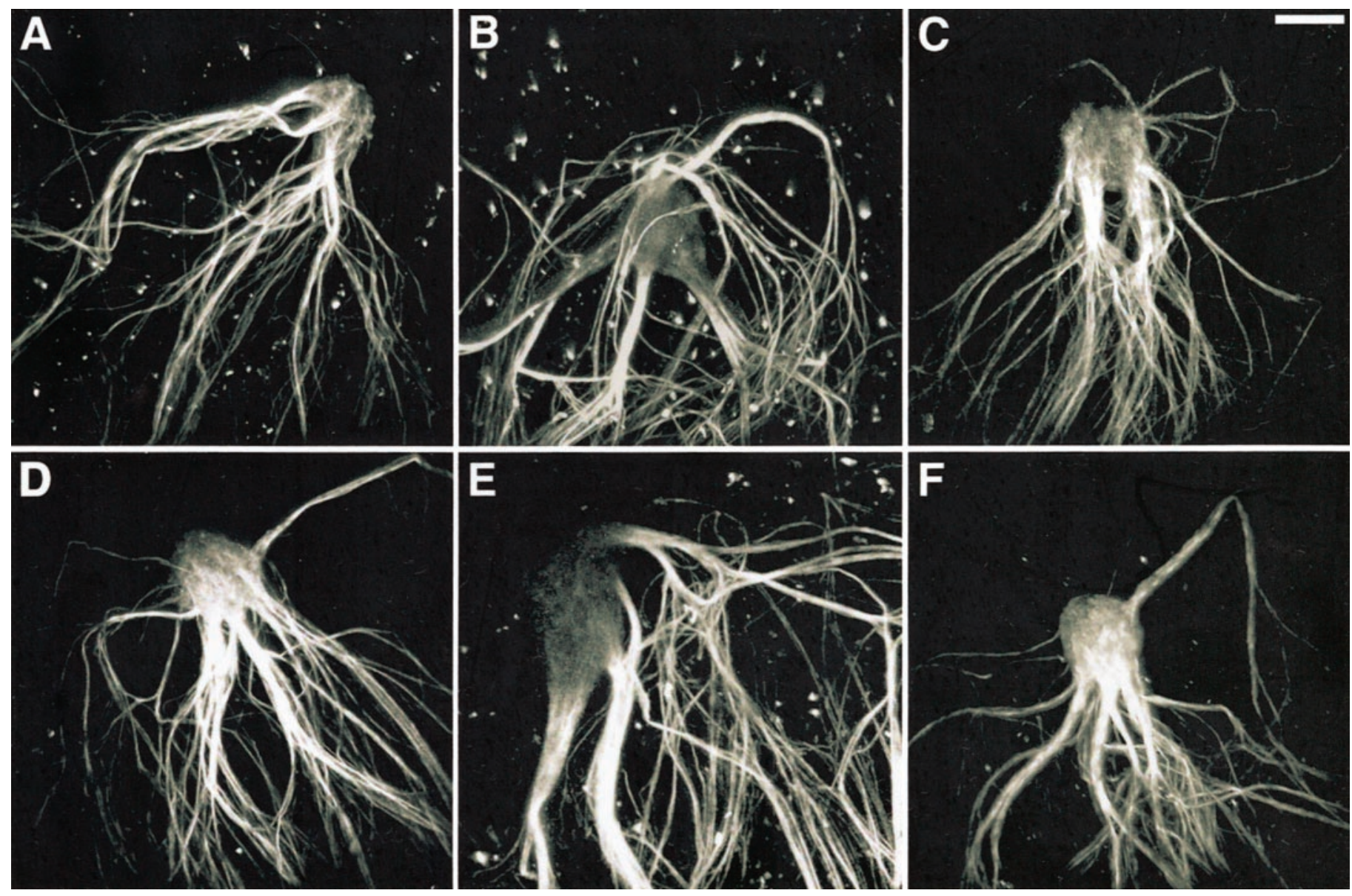

Figure 5. Glomeruli in mature M72-IRES-tauGFP mice. In these projections, the dorsolateral surface of the olfactory bulb is oriented toward the viewer and the rostral end of the nose is pointed toward the bottom. Each projection depicts an example of M72 glomeruli imaged in different individuals of PD18 or older. Image width, $\sim 256 \mu \mathrm{m}$; scale bar, $40 \mu \mathrm{m}$. $A-C$, Examples of mature M72 glomeruli in the lateral hemisphere of the right bulb. $D-F$, Examples of mature M72 glomeruli in the lateral hemisphere of the left bulb. These glomeruli receive their axonal input predominantly in the form of smaller fascicles. In some instances $(D, F)$, fascicles loop back onto the glomerulus (top right).

can be verified by tracing the smallest fibers in section series and in rotating or rocking animations of three-dimensional reconstructions of mature M72 glomeruli (animations 4-8, available at www.jneurosci.org). Because individual axons are easily detectable in the epithelium with TPLSM (Fig. $2 G$ ) and can be seen emanating from cell bodies in section series (animation 1, available at www.jneurosci.org), we are confident that we would have seen misrouted axons in mature mice had they existed.

\section{Phenotypic variability of M71 glomeruli}

To support our findings of the variable morphology of ORspecific axonal plexuses and glomeruli, we performed TPLSM analysis on another strain of gene-targeted mice carrying a M71IRES-tauGFP mutation (T. Bozza, P. Feinstein, C. Z heng, and P. Mombaerts, unpublished results). Figure 6 shows that, likewise, mature M71 glomeruli and axonal plexuses vary enormously in their morphological appearance. Thus, it is likely that phenotypic variability of OR-specific glomeruli is the rule rather than the exception across the glomerular array.

\section{Development of M72 glomeruli}

We performed a time course analysis of at least seven lateral glomeruli for each of the first 5 postnatal days in M72-IREStauGFP mice; the total data set is $>50$ glomeruli. A representative time course from PD1 to PD4 is shown in Figure 7, and examples of nascent M72 glomeruli imaged in both bulbs of the same individuals are shown in Figure 8. During PD1, a tangle of GFP-labeled fibers occupies a disproportionally large surface area $(150 \times 150 \mu \mathrm{m})$ of the dorsal region of the bulb. This tangle has no discernable organization or structure. During PD2, thickenings become apparent that may correspond to initiating condensations of axons. A protoglomerulus emerges in most cases between the end of PD2 and the beginning of PD3, with a distinct core that is $\sim 35 \mu \mathrm{m}$ in diameter. At PD4 and PD5, the nuclear structure is more elaborate and starts to resemble the configuration of a mature glomerulus. Although this was not a detailed study to determine whether misrouted axons transiently innervate neighboring glomeruli or whether they overshoot the glomerular layer, such errors in navigation do not appear to be a major part of the formation of M72 glomeruli. Thus, the M72 glomeruli coalesce rapidly in a highly timed manner from an apparently random tangle of axons.

\section{DISCUSSION}

\section{Development of the olfactory system}

Our morphological studies may exclude certain mechanistic principles of axon guidance, which operate in other model systems (Tessier-Lavigne and Goodman, 1996). First, because axons extend several millimeters and specifically target to a reproducible 

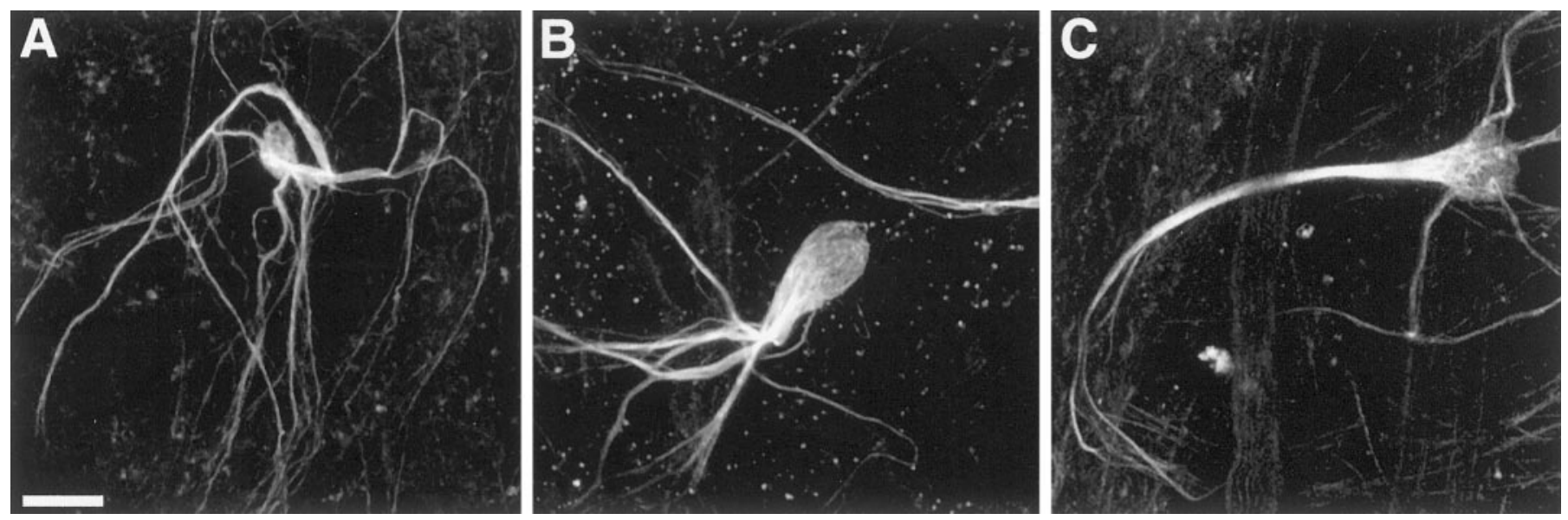

Figure 6. Glomeruli in mature M71-IRES-tauGFP mice. Three examples are shown. The architecture of the axonal plexuses and glomeruli is complex and variable.

set of glomeruli located at recognizable positions, arriving from widely dispersed areas in the bulb with varying degrees of fasciculation, it is unlikely that pathfinding relies on a small number of "pioneer" axons. Second, the apparent randomness of the fascicles suggest that selective fasciculation of axons expressing the same OR is not a determinant of axon guidance, at least not in the early stages of development. Third, the variability, heterogeneity, and apparent randomness of the axonal plexuses make it difficult to imagine that guidepost cells or "stepping stones" lead olfactory axons to their targets in the bulb.

What mechanisms then do these axons use to navigate to their target with such exquisite precision and reproducibility? Perhaps a hierarchically organized set of guidance molecules instructs the navigation of individual growth cones to a restricted area of the surface of the bulb. The images provided here, and in a related study documenting the development of P2 glomeruli (Royal and Key, 1999), allow us to infer two alternative scenarios for the final phase of target selection. Axons appear to be drawn in the vicinity of a specific site, resulting in a variable and heterogeneous axonal plexus. One interpretation is that soluble cues emanate from sites in the bulb, attracting individual axons from a distance independent of their entry point to the restricted area of the surface of the bulb ("chemotropic model"). In another scenario, growth cones sample the restricted area of the surface of the bulb until they arrive at their appropriate destination ("random search model"). In either case, the tight correlation between the nature of the expressed OR and the location of the glomerulus in the bulb supports the hypothesis that final target selection involves the ORs themselves. Indeed, results from genetic experiments have put forward the notion that the OR is intimately involved in the guidance process (Mombaerts et al., 1996a; Wang et al., 1998). The nature of the guidance mechanisms may relate to the convergence on a common target from an apparent random distribution in the periphery and to the persistence of neurogenesis throughout life: individual OSNs are continuously born in mature animals and must connect to the OR-specific glomeruli to preserve the constancy of the glomerular map (Gogos et al., 2000).

Our findings offer clear evidence of the accuracy and timing of patterning in the olfactory system and provide the needed backdrop for a future step of the analysis; we expect that dynamic information provided by time-lapse two-photon microscopy (Pot- ter, 2000) of mice at embryonic and postnatal stages will be even more fruitful in formulating models of axon guidance. For instance, four-dimensional imaging will allow us to evaluate to which extent axonal exuberance followed by pruning contributes to glomerular development (Klenoff and Greer, 1998).

\section{Heterogeneity in the olfactory system}

A detailed morphological description of the development of P2 glomeruli has been reported (Royal and Key, 1999): confocal laser scanning microscopy was applied on histological sections of P2-IRES-taulacZ mice (Mombaerts et al., 1996a) to image P2 glomeruli during development and in adult mice after staining with anti- $\beta$-galactosidase antibodies. An earlier time course for the development of P2 glomeruli was observed: glomerular structures can be discerned perinatally. This is consistent with the known asynchrony in glomerular development: in rat, a distinct rostral-to-caudal temporal gradient of glomerular development has been described previously (Bailey et al., 1999), such that morphological stages observable in the rostral-most region precede those in the caudal-most region by up to $4 \mathrm{~d}$. Because M72 and M71 glomeruli are located much more caudally than P2 glomeruli, it is perhaps not surprising that their development lags behind that of P2 glomeruli.

Another manifestation of heterogeneity is the differential impact on P2 and M72 glomeruli by targeted disruption of a cyclic nucleotide-gated channel subunit, which is essential for olfactory signal transduction. Although P2 glomeruli form apparently normally (Lin et al., 2000; Zheng et al., 2000), M72 glomeruli do not (Zheng et al., 2000). This may be related to temporal differences in the development of P2 and M72 glomeruli. Similarly, the developmental scenario of P2 glomeruli (Royal and Key, 1999) differs in at least three more aspects from our observations. First, the axonal tangle of P2-expressing OSNs appears early in development to occupy a more confined area than that of M72expressing OSNs. Second, P2 glomeruli emerge gradually over several days, which is slower and less abrupt than the PD2-PD3 transition that we observe typically for M72 glomeruli. Third, interconnected pairs of developing glomeruli resulting in doublets at adult stages are frequently observed for P2 glomeruli, at least by this group (Royal and Key, 1999). Although we have observed additional smaller M72 glomeruli (Zheng et al., 2000), we have no evidence that they are interconnected. 

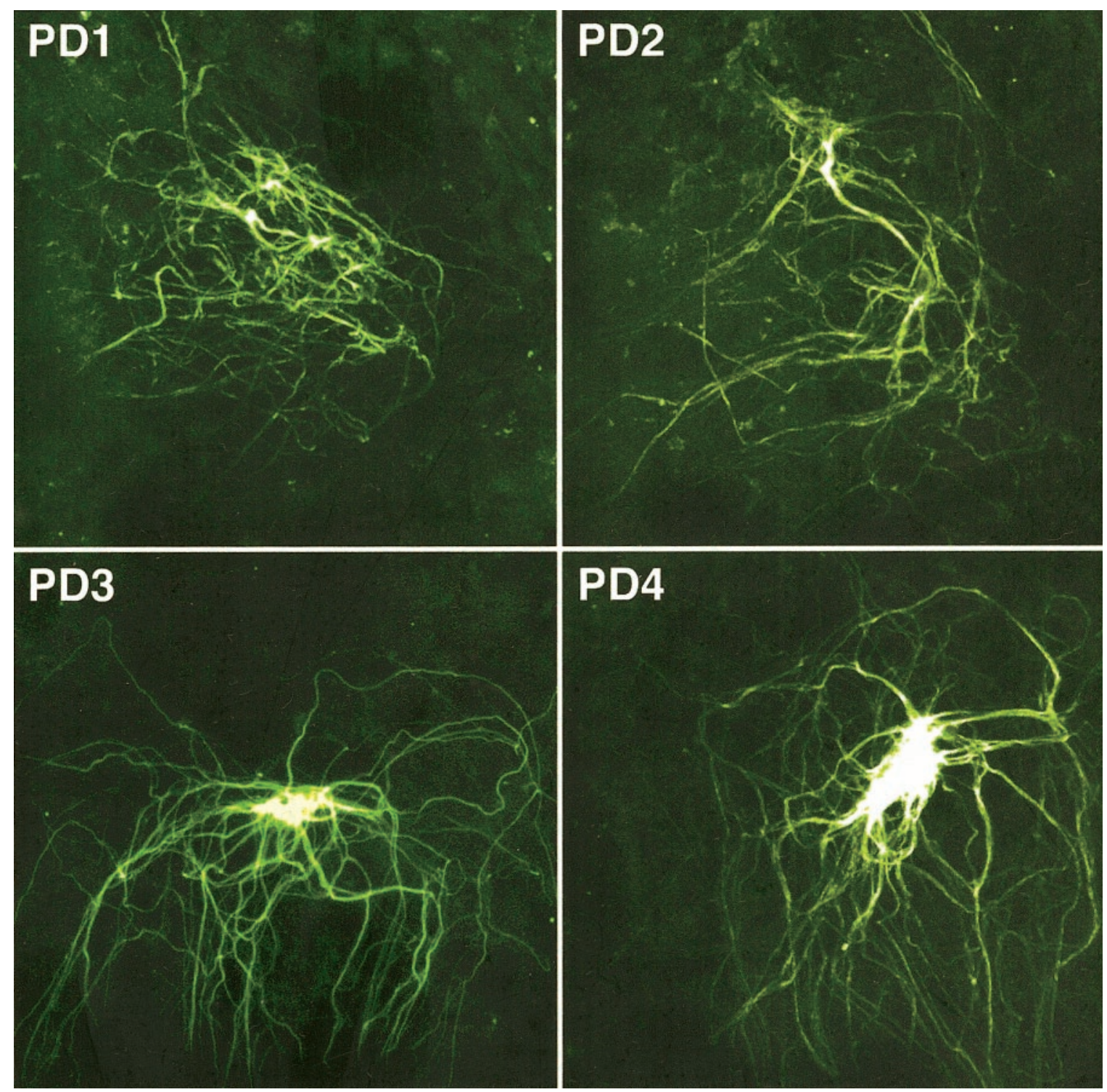

Figure 7. Postnatal development of M72 glomeruli. The montage shows coalescing M72 axons in four littermates at successive postnatal days. From a tangle of fibers at birth (PD1), a glomerular-like structure develops between PD2 and PD3.

\section{Glomerular convergence in the olfactory system}

It is now well established that populations of OSNs expressing a specific OR project their axons to specific glomeruli. The genetic strategy of tagging OR genes with IRES-taulacZ or IRES-tauGFP provided direct evidence for the principle of axonal convergence at the single-axon level (Mombaerts et al., 1996a). This approach has been applied in total to eight OR genes: P2 (Mombaerts et al., 1996a), M72 (Zheng et al., 2000), $m O R 37 A, m O R 37 B$, and $m O R 37 C$ (Strotmann et al., 2000), MOL2.3 (Conzelmann et al., 2000), MOR28 (Serizawa et al., 2000), and $M 71$ (this study). The common observation is that most, if not all, axons of OSNs expressing a specific OR project to a small number of glomeruli; in mature mice, misrouted axons are rare. Typically convergence occurs on one or a few glomeruli in each hemisphere of the bulb, thus at least four glomeruli per mouse. Exceptions are the mOR37 genes, which correspond typically to one glomerulus per bulb (Strotmann et al., 2000). Additional glomeruli are often seen, but the number of labeled glomeruli in P2-IRES-taulac Z mice varies among laboratories (Mombaerts et al., 1996a; Royal and Key, 1999; Costanzo, 2000; Lin et al., 2000; Zheng et al., 2000; Schaefer et al., 2001), possibly reflecting genetic drift of the strain, variations in the odorous environment of animal facilities or methodological differences.

The wealth of available strains with targeted mutations of the type OR-IRES-tau (marker) is in contrast with the lack of detailed information about the organization and development of plexuses and glomeruli, acquired with advanced imaging techniques. This study provides three-dimensional reconstructions of OR-specific glomeruli and applies TPLSM to this objective. The images provide a much better appreciation of the idiosyncratic morphology of OR-specific glomeruli and their plexuses. It would be informative to apply TPLSM combining GFP detection of OSN axons with immunofluorescence for markers of the other cellular components (mitral and tufted cells, radial glia and astrocytes, and juxtaglomerular neurons), as described in other imaging studies of glomeruli (Bailey et al., 1999; Treloar et al., 1999). 
A
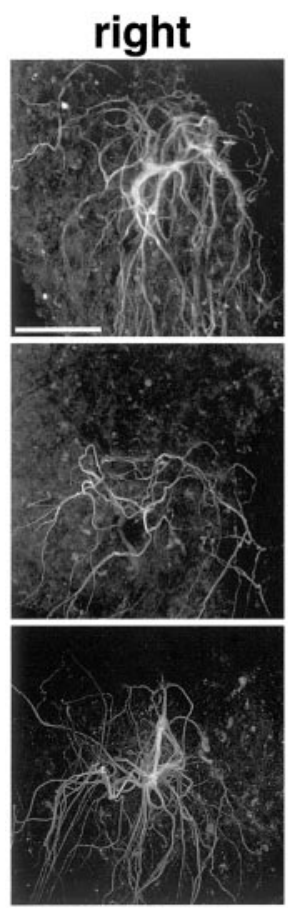
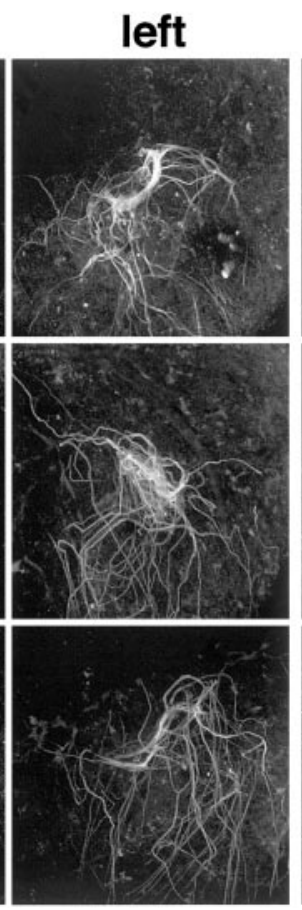

B
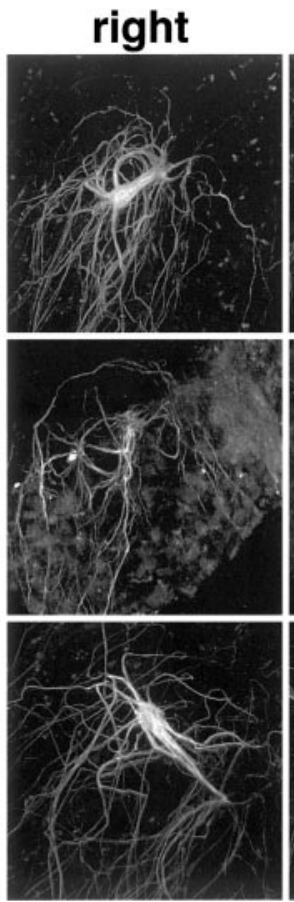

C

left
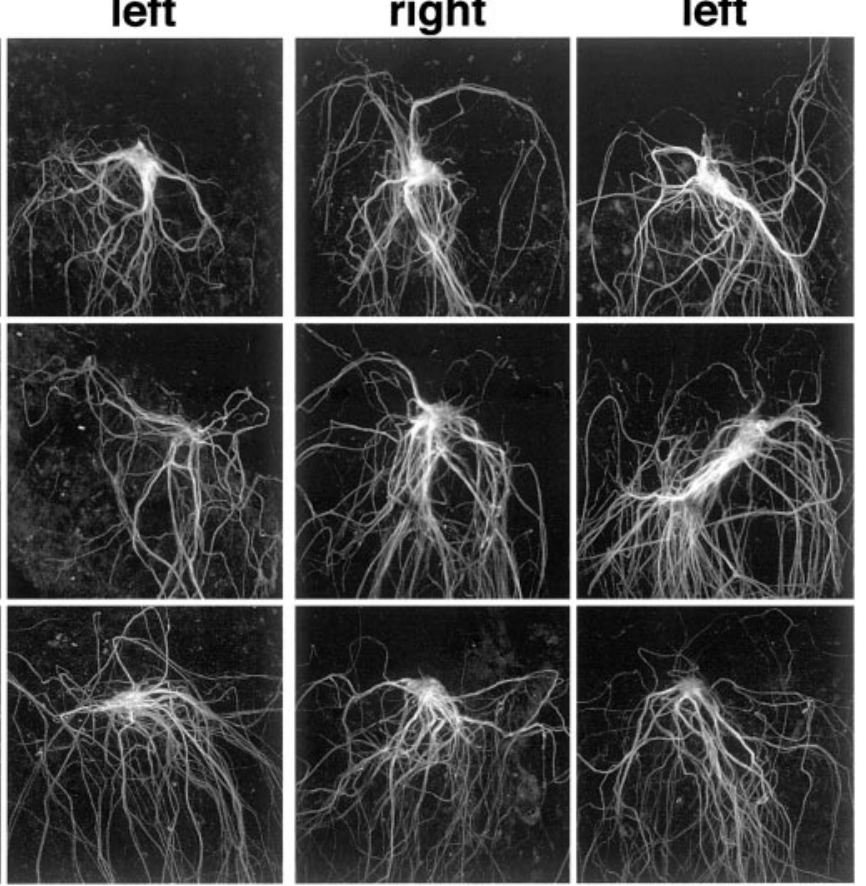
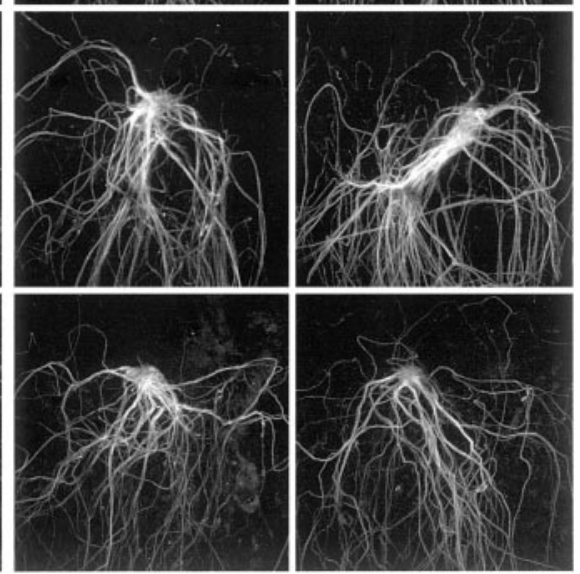

Figure 8. Right-left pairs of developing M72 glomeruli. The right and left lateral M72 glomeruli within different individual mice were imaged on PD2 $(A)$, PD3 $(B)$, or PD5 $(C)$. The dorsolateral surface of the olfactory bulb is oriented toward the viewer, and the rostral extreme of the nose is pointed toward the bottom. Image width, $256 \mu \mathrm{m}$; scale bar, $80 \mu \mathrm{m}$. $A$, Lateral M72 glomeruli in three PD2 mice. Each row represents the right and left lateral M72 glomeruli within an individual mouse. Converging M72 axons are clearly visible; however, a glomerular-like structure is not obvious and may not have stabilized by this stage. $B$, Lateral M72 glomeruli in three PD3 mice. M72 glomerular-like structures become visible as M72 axons converge and stabilize their target glomeruli. $C$, Lateral M72 glomeruli in three PD5 mice. A glomerular-like structure has formed and is clearly visible.

\section{A genetic approach to neuroanatomy}

Targeted integration of an IRES-tauGFP cassette ensures correct spatiotemporal regulation of marker expression without the need to know the regulatory elements that control expression of the target gene. An additional rationale for using an IRES strategy (Mombaerts, 1996) is monoallelic expression of OR genes (Chess et al., 1994). A red fluorescent protein has been characterized in another marine species (Matz et al., 1999). New tools pave the way for multicolor imaging of distinct neuronal populations within the same genetically engineered mouse (Feng et al., 2000).

TPLSM is the preferred method for repeated threedimensional imaging of thick, unfixed, optically scattering biological specimens (Denk et al., 1990; Denk and Svoboda, 1997; Potter, 2000). GFP expression lends itself very well to imaging by TPLSM (Potter et al., 1996). We have shown here that imaging olfactory glomeruli in whole-mount specimens of mice is well suited to TPLSM. The signal from a single GFP-labeled axon can be detected unambiguously by TPLSM using light that is below the threshold for phototoxic effects. The size of the glomeruli $(\sim 80 \mu \mathrm{m})$ and their depth from the surface $(\sim 200 \mu \mathrm{m})$ necessitates the use of TPLSM, because these dimensions exceed the capabilities of confocal laser scanning microscopy. The images presented in this study, with two exceptions (Fig. 2C,D), were derived from unfixed, acutely dissected whole-mount specimens of neonatal and mature mice and not from histological sections.

\section{Conclusion}

The emerging realization of heterogeneity suggests the need for a more systematic examination of OR-specific glomeruli. This has become feasible by the generation of gene-targeted strains of mice with mutations of the OR-IRES-marker type in any of several OR genes (Mombaerts et al., 1996a; Conzelmann et al., 2000; Serizawa et al., 2000; Strotmann et al., 2000; Zheng et al. 2000; this study). Thus, although the heterogeneity and complexity of the olfactory system have precluded a systematic analysis in the past, new approaches solve these challenges by selective imaging of a single OR-specific population of OSNs.

\section{REFERENCES}

Bailey MS, Puche AC, Shipley MT (1999) Development of the olfactory bulb: evidence for glia-neuron interactions in glomerular formation. J Comp Neurol 415:423-448

Brand A (1995) GFP in Drosophila. Trends Genet 11:324-325.

Buck L, Axel R (1991) A novel multigene family may encode odorant receptors: a molecular basis for odor recognition. Cell 65:175-187.

Callahan CA, Thomas JB (1994) Tau-beta-galactosidase, an axontargeted fusion protein. Proc Natl Acad Sci USA 91:5972-5976.

Chalfie M, Tu Y, Euskirchen G, Ward WW, Prasher DC (1994) Green fluorescent protein as a marker for gene expression. Science 263:802-805.

Chess A, Simon I, Cedar H, Axel R (1994) Allelic inactivation regulates olfactory receptor gene expression. Cell 78:823-834.

Conzelmann S, Levai O, Bode B, Eisel U, Raming K, Breer H, Strotmann $\mathrm{J}$ (2000) A novel brain receptor is expressed in a distinct population of olfactory sensory neurons. Eur J Neurosci 12:3926-3934.

Costanzo RM (2000) Rewiring the olfactory bulb: changes in odor maps following recovery from nerve transection. Chem Senses 25:199-205.

Denk W, Svoboda K (1997) Photon upmanship: why multiphoton imaging is more than a gimmick. Neuron 18:351-357.

Denk W, Strickler JH, Webb WW (1990) Two-photon laser scanning fluorescence microscopy. Science 248:73-76.

Dynes JL, Ngai J (1998) Pathfinding of olfactory neuron axons to stereotyped glomerular targets revealed by dynamic imaging in living zebrafish embryos. Neuron 20:1081-1091. 
Feng G, Mellor RH, Bernstein M, Keller-Peck C, Nguyen QT, Wallace M, Nerbonne JM, Lichtman JW, Sanes JR (2000) Imaging neuronal subsets in transgenic mice expressing multiple spectral variants of GFP. Neuron 28:41-51.

Gogos JA, Osborne J, Nemes A, Mendelsohn M, Axel R (2000) Genetic ablation and restoration of the olfactory topographic map. Cell 103:609-620.

Hooper ML, Hardy K, Handyside A, Hunter S, Monk M (1987) HPRTdeficient (Lesch Nyhan) mouse embryos derived from germline colonization by cultured cells. Nature 326:292-295.

Klenoff JR, Greer CA (1998) Postnatal development of olfactory receptor cell axonal arbors. J Comp Neurol 390:256-267.

Lakso M, Pichel JG, Gorman JR, Sauer B, Okamoto Y, Lee E, Alt FW, Westphal H (1996) Efficient in vivo manipulation of mouse genomic sequences at the zygote stage. Proc Natl Acad Sci USA 93:5860-5865.

LaMantia AS, Purves D (1989) Development of glomerular pattern visualized in the olfactory bulbs of living mice. Nature 341:646-649.

LaMantia AS, Pomeroy SL, Purves D (1992) Vital imaging of glomeruli in the mouse olfactory bulb. J Neurosci 12:976-988.

Lin DM, Wang F, Lowe G, Gold GH, Axel R, Ngai J, Brunet L (2000) Formation of precise connections in the olfactory bulb occurs in the absence of odorant-evoked activity. Neuron 26:69-80.

Malnic B, Hirono J, Sato T, Buck LB (1999) Combinatorial receptor codes for odors. Cell 96:713-723.

Malun D, Brunjes PC (1986) Development of olfactory glomeruli: temporal and spatial interactions between olfactory receptor axons and mitral cells in opossums and rats. J Comp Neurol 22:1-16.

Margolis FL (1972) A brain protein unique to the olfactory bulb. Proc Natl Acad Sci USA 69:1221-1224.

Matz MV, Fradkov AF, Labas YA, Savitsky AP, Zaraisky AG, Markelov ML, Lukyanov SA (1999) Fluorescent proteins from nonbioluminescent Anthozoa species. Nat Biotechnol 17:969-973.

Mombaerts P (1996) Targeting olfaction. Curr Opin Neurobiol 6:481-486.

Mombaerts P (1999a) Molecular biology of odorant receptors in vertebrates. Annu Rev Neurosci 22:487-509.

Mombaerts P (1999b) Seven-transmembrane proteins as odorant and chemosensory receptors. Science 286:707-711.

Mombaerts P (2000) The human repertoire of odorant receptor genes and pseudogenes. Annu Rev Genom Hum Genet 2:493-501.

Mombaerts P (2001) How smell develops. Nat Neurosci 4:1192-1198.

Mombaerts P, Wang F, Dulac C, Chao SK, Nemes A, Mendelsohn M, Edmondson J, Axel R (1996a) Visualizing an olfactory sensory map. Cell 87:675-686.

Mombaerts P, Wang F, Dulac C, Vassar R, Chao SK, Nemes A, Mendelsohn M, Edmondson J, Axel R (1996b) The molecular biology of olfactory perception. Cold Spring Harb Symp Quant Biol 61:135-145.

Oland LA, Tolbert LP (1996) Multiple factors shape development of olfactory glomeruli: insights from an insect model system. J Neurobiol 30:92-109.

Potter SM (1996) Vital imaging: two photons are better than one. Curr Biol 6:1595-1598.

Potter SM (2000) Two-photon microscopy for 4D imaging of living neurons. In: Imaging neurons: a laboratory manual. (Yuste R, Lanni F, Konnerth A, eds), pp 20.1-20.16. Cold Spring Harbor, NY: Cold Spring Harbor Laboratory.
Potter SM, Wang CM, Garrity PA, Fraser SE (1996) Intravital imaging of green fluorescent protein using two-photon laser-scanning microscopy. Gene 173:25-31.

Puche AP, Shipley MT (2001) Radial glia development in the mouse olfactory bulb. J Comp Neurol 434:1-12.

Ramón y Cajal S (1911) Appareil olfactif. Muqueuse olfactive et bulbe olfactif ou centre olfactif de premier ordre. In: Histologie du système nerveux de l'homme et des vertébrés, Vol 2, pp 647-674. Paris: Maloine.

Ressler KJ, Sullivan SL, Buck LB (1993) A zonal organization of odorant receptor gene expression in the olfactory epithelium. Cell 73:597-609.

Ressler KJ, Sullivan SL, Buck LB (1994) Information coding in the olfactory system: evidence for a stereotyped and highly organized epitope map in the olfactory bulb. Cell 79:1245-1255.

Rodriguez I, Feinstein P, Mombaerts P (1999) Variable patterns of axonal projections of sensory neurons in the mouse vomeronasal system. Cell 97:199-208.

Royal SJ, Key B (1999) Development of olfactory glomeruli in P2internal ribosome entry site-tau-lacZ transgenic mice. J Neurosci 19:9856-9864.

Royet JP, Souchier C, Jourdan F, Ploye H (1988) Morphometric study of the glomerular population in the mouse olfactory bulb: numerical density and size distribution along the rostrocaudal axis. J Comp Neurol 270:559-568.

Schaefer ML, Finger TE, Restrepo D (2001) Variability in position of the P2 glomerulus within a map of the mouse olfactory bulb. J Comp Neurol 436:350-361.

Serizawa S, Ishii T, Nakatani H, Tsuboi A, Nagawa F, Asano M, Sudo K, Sakagami S, Sakano H, Ijiri T, Matsuda Y, Suzuki M, Yamamori T, Iwakura Y, Sakano H (2000) Mutually exclusive expression of odorant receptor transgenes. Nat Neurosci 3:638-639.

Strotmann J, Conzelmann S, Beck A, Feinstein P, Breer H, Mombaerts P (2000) Local permutations in the glomerular array of the mouse olfactory bulb. J Neurosci 20:6927-6938.

Tessier-Lavigne M, Goodman CS (1996) The molecular biology of axon guidance. Science 274:1123-1133.

Treloar HB, Purcell AL, Greer CA (1999) Glomerular formation in the developing rat olfactory bulb. J Comp Neurol 413:289-304.

Tsien RY (1998) The green fluorescent protein. Annu Rev Biochem 67:509-544.

Valverde F, Santacana M, Heredia M (1992) Formation of an olfactory glomerulus: morphological aspects of development and organization. Neuroscience 49:255-275.

Vassar R, Ngai J, Axel R (1993) Spatial segregation of odorant receptor expression in the mammalian olfactory epithelium. Cell 74:309-318.

Vassar R, Chao SK, Sitcheran R, Nuñez JM, Vosshall LB, Axel R (1994) Topographic organization of sensory projections to the olfactory bulb. Cell 79:981-991.

Wang F, Nemes A, Mendelsohn M, Axel R (1998) Odorant receptors govern the formation of a precise topographic map. Cell 93:47-60.

Zheng C, Feinstein P, Bozza T, Rodriguez I, Mombaerts P (2000) Peripheral olfactory projections are differentially affected in mice deficient in a cyclic nucleotide-gated channel subunit. Neuron 26:81-91. 